\title{
Non-Neoplastic Heart Disorder
}

National Cancer Institute

\section{Source}

National Cancer Institute. Non-Neoplastic Heart Disorder. NCI Thesaurus. Code C35741.

A non-neoplastic disorder that affects the heart and/or the pericardium. Representative examples include congestive heart disease, endocarditis, and constrictive pericarditis. 